\title{
Multiple-Stage Mass Spectrometry in Structural Characterization of Organophosphorus Compounds
}

\author{
Loreen C. Zeller, John T. Farrell, Jr.*, and Hilkka I. Kenttämaa \\ Department of Chemistry, Purdue University, West Lafayette, Indiana, USA
}

Tuula Kuivalainen

Department of Chemistry, University of Helsinki, Helsinki, Finland

\begin{abstract}
Multiple-stage mass spectrometry involving consecutive collision-activated dissociation reactions was used to examine the structures of fragment ions commonly formed on electron ionization of organophosphorus esters. The compounds studied include several aryl thiophosphates, some of which are analogs of common pesticides. Energy-resolved collisionactivated dissociation experiments allow the dissociation of the molecular ions of these compounds in such a manner that only a few fragment ions dominate the spectrum. An abundant fragment ion of $m / z$ 109, formed from all of the compounds studied, can have at least four different stable structures: $\left(\mathrm{CH}_{3} \mathrm{O}\right)_{2} \mathrm{PO}^{+}, \mathrm{CH}_{3} \mathrm{CH}_{2} \mathrm{OP}\left(\mathrm{O}^{2} \mathrm{OH}^{+}\right.$, $\mathrm{CH}_{2}=\mathrm{CHOP}(\mathrm{H})(\mathrm{OH})_{2}^{+}$, and $\left(\mathrm{CH}_{2} \mathrm{O}\right)_{2} \mathrm{P}\left(\mathrm{H} \mathrm{OH}^{+}\right.$. The structure of the fragment ion of $\mathrm{m} / z 109$ was found to reflect the phosphorus-containing part of the compounds studied. Another abundant fragment ion obtained for all the aryl esters studied is structurally characteristic of the aromatic moiety of the molecule. This fragment ion is the result of a complex rearrangement involving transfer of an alkylene group to the aromatic ring from the phosphoruscontaining part of the molecular ion. The utility of these fragment ions in the structural characterization of unknown organophosphorus esters is discussed. (I Am Soc Mass Spectrom $1993,4,125-134)$
\end{abstract}

$\mathrm{T}$ he identification and quantification of organophosphorus compounds, such as pesticides, plasticizers, pharmaceuticals, and lubricants [1], as well as their degradation products and metabolites in environmental and biological samples, is an analytical problem of increasing importance. Mass spectrometry is a particularly useful technique for solving these problems owing to its potential for trace analysis of compounds in complex matrices. Previous mass spectrometric studies of organophosphorus compounds have focused primarily on data generated by electron ionization and chemical ionization of neutral compounds [2-7], although a few excellent publications dealing with tandem mass spectrometry (MS/MS) experiments have also appeared [5]. Chemical ionization generally results in less structurally informative fragmentation than electron ionization [8-11], which limits the usefulness of this method in structural characterization of unknown molecules. Electron ionization yields numerous fragment ions, however, interpretation of the electron ionization mass spectra of

*Present address: Department of Chemistry, University of Colorado. Boulder, CO 80309

Address reprint requests to Hilkka I. Kenttämaa, Department of Chemistry, Purdue University, West Lafayette, IN 47907-1393. organophosphorus compounds is often complicated by the low abundance or even absence of structurally informative high-mass ions. The more abundant lowmass ions do not have well-established structures, and the mechanisms of the reactions leading to these ions are largely unknown.

We have used multiple-stage mass spectrometry to examine the structures of low-mass fragment ions common to ionized phosphorus esters. The focus of this study is on aryl thiophosphates; some of the compounds studied are closely related to commonly used pesticides. Our work demonstrates that energyresolved collision-activated dissociation (CAD) of ionized aryl phosphates allows the generation of spectra that are dominated by only a few low-mass fragment ions. The structural characterization of these fragment ions can provide valuable structural information about their neutral precursors.

\section{Experimental}

The aromatic phosphorus esters were synthesized by one of the authors (T. K.) by using common laboratory procedures. The structures were verified by NMR and mass spectrometry [12], and the purity was checked by 
gas chromatography. All of the reagents were used as received from the manufacturer without further purification. Ethylene phosphonate, trimethyl phos phate, triethyl phosphate (99.5\%), and triethyl phosphite $(98.5 \%)$ were obtained from ChemService (West Chester, PA). Toluene, styrene, 4-chlorotoluene, and 2-chlorotoluene were obtained from Aldrich Chemical Co. (Milwaukee, WI). Trimethyl thiophosphate and tri-isopropyl phosphite were obtained from Alfa Products (Danvers, MA). Toluene (Mallincrodt, Paris, KY), trimethyl phosphite (Strem Chemicals, Inc., Newburyport, MA), $\mathrm{ND}_{3}$ (Matheson, Secaucus, NJ), and $\mathrm{d}_{\mathrm{g}}$-isopropanol (Cambridge Isotopes, Woburn, MA) were also used.

All of the experiments were carried out on a Fourier transform-ion cyclotron resonance (FT-ICR) mass spectrometer and a triple quadrupole instrument. The FT-ICR instrument (a prototype Extrel FTMS-2001) has been described previously [13]. This instrument has a differentially pumped dual cell aligned collinearly with a magnetic field of $2.9 \mathrm{~T}$. The two cells are separated by a conductance limit plate containing a 2-mm hole in the center. Grounding this plate allows the transfer of the ions through the hole from one cell into the other. At all other times, the same voltage $(+2 \mathrm{~V})$ was applied to the conductance limit plate and to the two trapping plates perpendicular to the magnetic field lines.

All of the compounds were introduced into the FT-ICR mass spectrometer at a nominal pressure of approximately $1 \times 10^{-7}$ torr by using a heated prototype batch inlet system equipped with a leak valve, a manual solids probe, or a Varian leak valve. Molecular ions were generated by 12-15 eV electron ionization for approximately $5 \mathrm{~ms}$, unless otherwise specified. Protonated molecules were produced by self-chemical ionization, wherein the fragment ions generated by electron ionization of the sample are allowed to protonate the neutral sample molecules, or by $\mathrm{NH}_{3}$ chemical ionization ( $4 \mathrm{~s}$ reaction time). The reagent gas pressure was adjusted to ensure that the base peak in the chemical ionization mass spectrum was that of the protonated molecule rather than that of the adduct of ammonium ion and the neutral molecule.

A typical experiment sequence consisted of generation of the ions in one side of the dual cell (source cell) by electron ionization, followed by transfer of the ions into the other cell (analyzer cell). Cations generated in the analyzer cell during the electron beam event were eliminated from the cell prior to ion transfer by applying a negative potential $(-10 \mathrm{~V})$ to the analyzer trap plate for a variable length of time (typically 5-10 ms). In the analyzer cell, the ions of interest were isolated by applying a sequence of voltage pulses to the analyzer cell excitation plates. Frequency sweeps and single-frequency ejection pulses were used to remove undesirable ions by accelerating them until they hit the walls of the cell and lost their charge.

Collision-activated dissociation was carried out on the isolated ions by using an excitation pulse of a fixed amplitude ( $3 \mathrm{~V}$ ), variable duration (typically 50-300 $\mu \mathrm{s}$ ), and a frequency corresponding to the cyclotron frequency of the ion of interest. The CAD excitation pulse was followed by a reaction time of $100 \mathrm{~ms}$, unless otherwise specified. During this reaction time, collisions of the ion with argon (nominal pressure of $1 \times 10^{-7}$ torr) convert ion kinetic energy into internal energy, causing the ion to dissociate. Variation of the duration of the excitation pulse controls the final kinetic energy of the ion. Energy-resolved $\mathrm{CAD}$ spectra were generated by plotting the abundance of each fragment ion normalized to the total fragment ion current as a function of the laboratory kinetic energy of the parent ions. All ion kinetic energies reported in this work are laboratory kinetic energies and were calculated by using the method of Grosshans and Marshall [14]. At a nominal collision gas pressure of $1 \times 10^{-7}$ torr and laboratory collision energies of 5-50 eV, ions of $m / z \quad 109$ undergo an average of two to five collisions during the $100-\mathrm{ms}$ reaction time. ${ }^{1}$

Three-stage mass spectrometry (MS ${ }^{3}$ ) experiments were carried out by generating the parent ion in the source cell. After transfer into the analyzer cell, the parent ions were isolated by using the method described earlier. Collisional activation of the parent ions then produced fragment ions that were isolated and collisionally activated in the same cell.

The spectra illustrated are an average of at least 50 spectra, acquired by taking $32 \mathrm{~K}$ data points per scan at a digitizer rate of $5.3 \mathrm{MHz}$. The excitation sweep (chirp) had a bandwidth of $2.7 \mathrm{MHz}$ and an amplitude of $105 \mathrm{~V}$. The sweep rate was $3.2 \mathrm{kHz} / \mu \mathrm{s}$. The spectra were subjected to one zero fill prior to Fourier transformation.

Some CAD experiments for the reference ions of $m / z \quad 109$ were performed on a Finnigan triple quadrupole mass spectrometer (Finnigan-MAT TSQ 4500 , San Jose, CA) [15, 16]. Ions were generated by using electron or chemical ionization. Isobutane (nominal pressure 0.4 torr) was used as the chemical ionization reagent. The mass spectrometer was operated in the daughter ion scan mode [16]. Argon was used as the collision gas in the center quadrupole at a nominal pressure of less than $0.1 \times 10^{-3}$ torr for single-collision experiments [17]. In this device, the collision energy is defined by the potential difference between the ion source and the center quadrupole.

\section{Results and Discussion}

Figure 1 illustrates a multiple-stage mass spectrometry $\left(\mathrm{MS}^{n}\right)$ experiment involving four successive steps of

\footnotetext{
${ }^{1}$ The number of collisions per second $(Z)$ was calculated by using the following equation: $Z=\left(4.5 \times 10^{8}\right.$ torr $\left.^{-1} \mathrm{eV}^{-1 / 2} \mathbf{u}^{-1 / 2} \mathrm{~s}^{-1}\right)$ $\left(P_{\text {torr }}\right)\left(R_{\mathrm{IG}}\right)\left[\mathrm{KE}_{\mathrm{est}, \mathrm{eV}} /(\mathrm{m} / z)\right]^{1 / 2}$, where $P_{\mathrm{torr}}$ is the ion gauge pressure (torr); $R_{\mathrm{IG}}$ the geometry correction factor for the ionization gauges (reagent dependent); and $\mathrm{KE}_{\text {est, } \mathrm{eV}}$ the estimated (see ref 13) collision energy $(\mathrm{eV})$.
} 


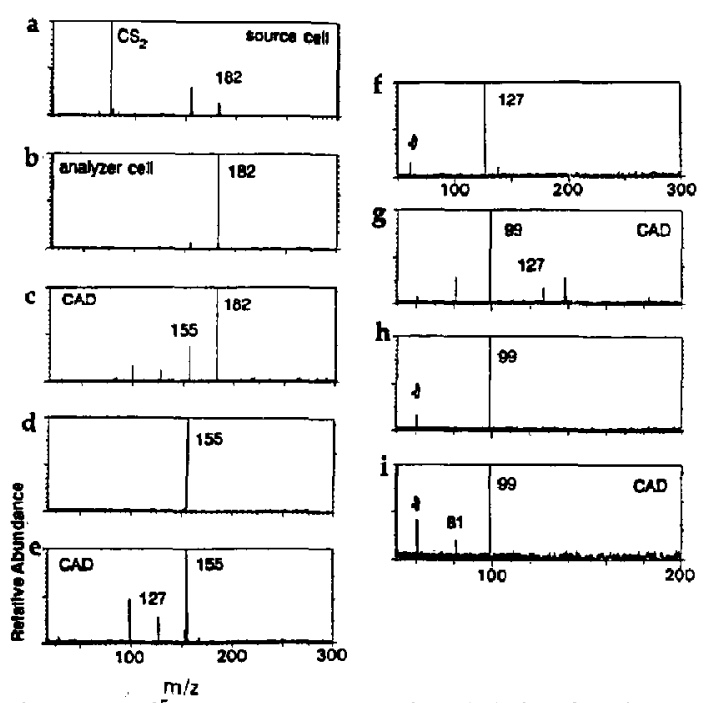

Figure 1. MS ${ }^{5}$ experiment for ionized triethyl phosphate (generated by $\mathrm{CS}_{2}^{+\cdot}$ charge exchange) showing consecutive steps of isolation and $\mathrm{CAD}$ of the molecular ion of triethyl phosphate $(m / z 182)$ and its dissociation products. The reaction sequence shown is $182^{+} \rightarrow 155^{+} \rightarrow 127^{+} \rightarrow 99^{+} \rightarrow 81^{+}$. The symbol $\&$ indicates interference caused by a local radio station.

ion isolation and CAD for a simple organophosphorus ester. Analogous experiments were used to obtain structural information for the low-mass fragment ions of several organophosphorus esters. Energy-resolved CAD experiments performed on the ionized compounds were adjusted such that only a small amount of energy was deposited in the fragmenting ion. This results in greatly simplified fragmentation dominated by the formation of only a few fragment ions that were found to be common for the compounds studied (Figure 2c). One of these, a fragment ion of $m / z 109$, yields information about the phosphorus-containing part of the molecule, whereas another fragment ion, the mass of which varies predictably depending on various structural characteristics (e.g., $m / z 125$ in Figure $2 c$ ), yields information about the aromatic moiety of the molecular ion. The following discussion is divided into three sections: the first two sections focus on the two different types of major fragment ions produced by the compounds studied, and the third section focuses on fragmentation characteristics of protonated esters.

\section{Phosphorus-Containing Fragment Ion}

A fragment ion of $m / z 109$ is commun to many organophosphorus compounds and was found in the electron ionization mass spectra of all of the aryl esters studied. The structure of this ion was examined by comparing its dissociation reactions to those of reference ions of known structures. Reference ions of $m / z 109$ with different isomeric structures were generated by electron ionization of trimethyl phosphate, a
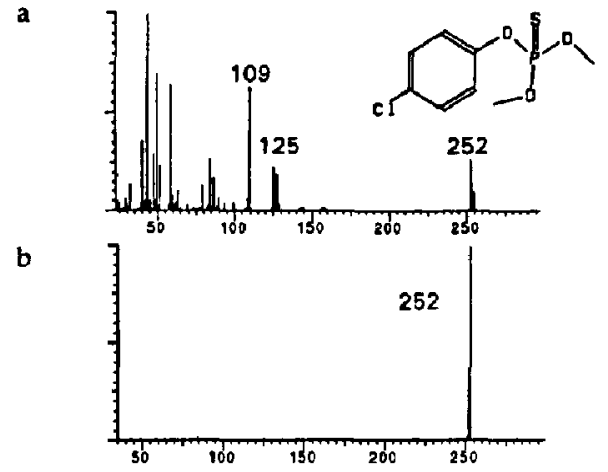

c
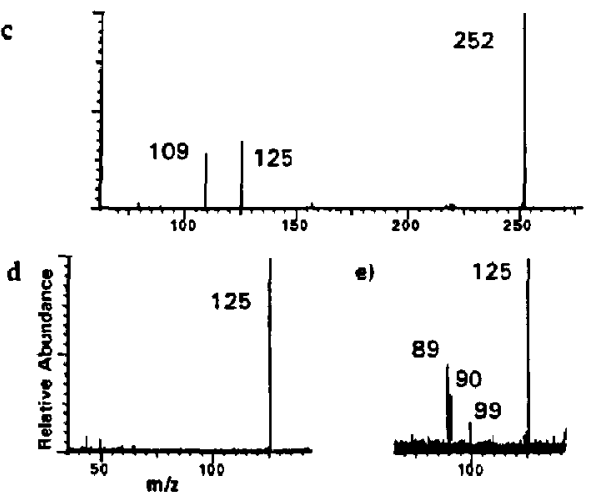

Figure 2. $\mathrm{MS}^{3}$ experiment for dimethyl 4-chlorophenyl thiophosphate: (a) $12 \mathrm{eV}$ electron ionization mass spectrum; (b) isolation of the molecular ion of $m / z$ 252; (c) $30 \mathrm{eV}$ CAD of the molecular ion; (d) isolation of the fragment ion of $m / z$ 125; (e) 40 eV CAD of the fragment ion of $m / z 125$. Argon was used as the collision gas at a nominal pressure of $1 \times 10^{-7}$ torr; reaction time was $100 \mathrm{~ms}$.

trimethyl thiophosphate, trimethyl phosphite, triethyl phosphate, triethyl phosphite, tri-isopropyl phosphite, and dimethyl propyl phosphate and by chemical ionization of ethylene phosphonate (Scheme I). The reference ions obtained from the cyclic, tri-isopropyl, ethyl, and methyl esters all produce different, structurally characteristic energy-resolved CAD spectra (Figure 3). Similar fragmentation patterns were measured on the FT-ICR and the triple quadrupole instruments.

The dimethyl isomer of $\mathrm{m} / z 109$ (Figure 3a) is generated from trimethyl phosphate, trimethyl phosphite, trimethyl thiophosphate, and dimethyl propyl phosphate [20-22]. This ion characteristically loses formaldehyde to yield the fragment ion $\mathrm{CH}_{3} \mathrm{OPOH}^{+}$ of $m / z 79$. Al the relatively low CAD energies used in the triple quadrupole instrument at the single-collision conditions chosen here, the fragment ion of $\mathrm{m} / \mathrm{z} 79$ dominates the dissuciation product distribution of the ion of $m / z$ 109. The ethyl isomer of $m / z 109$ (Figure $3 b)$ generated from triethyl phosphate and triethyl phosphite predominantly loses ethylene (to yield an ion of $\mathrm{m} / \mathrm{z} 81)$, a reaction characteristic of even-electron phosphorus ions containing ethyl groups. At low excitation energies, loss of water yields $\mathrm{C}_{2} \mathrm{H}_{4} \mathrm{O}_{2} \mathrm{P}^{+}(\mathrm{m} / \mathrm{z}$ 91), and at high excitation energies, a fragment ion 

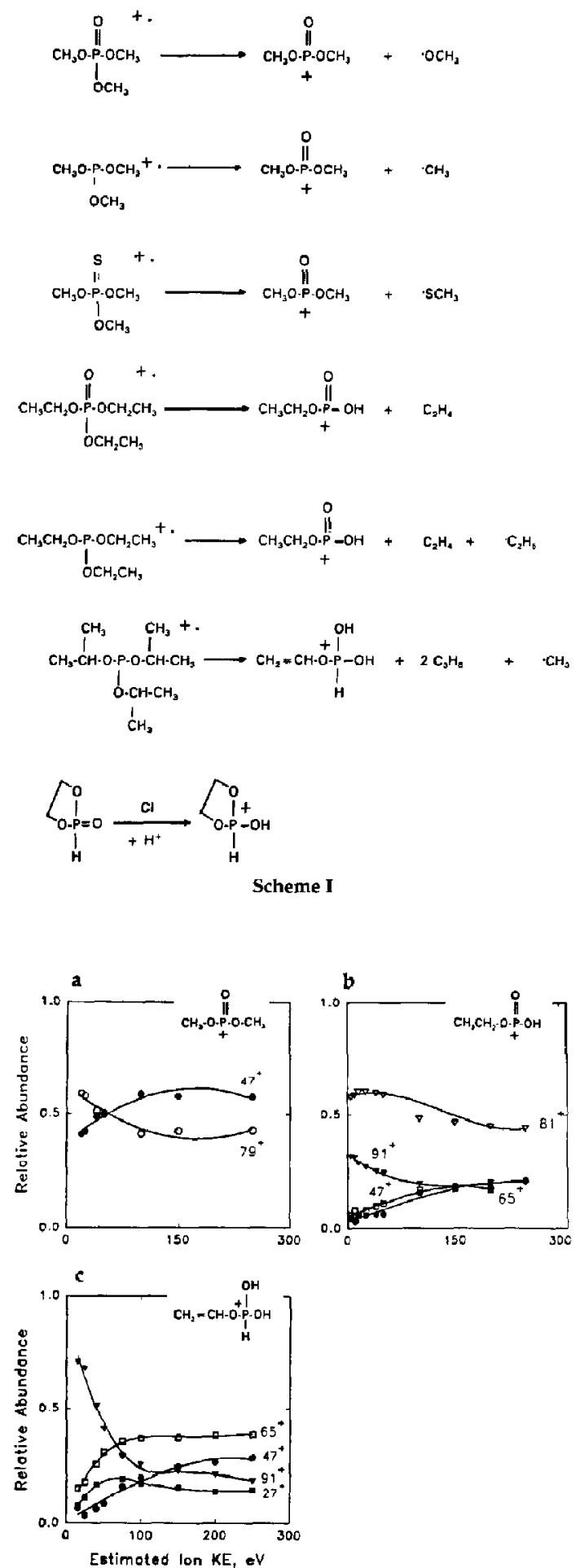

Figure 3. Energy-resolved mass spectra of three reference ions of $m / z$ 109: (a) the dimethyl isomer produced from trimethyl phosphate; (b) the ethyl isomer produced from triethyl phosphate; (c) the vinyl isomer produced from tri-isopropyl phosphite.
$\mathrm{PO}_{2} \mathrm{H}_{2}^{+}(m / z \quad 65)$ is also observed. In the triple quadrupole instrument, the fragment ion of $\mathrm{m} / z$ 91 dominates the dissociation patterns. A third isomer of $m / z 109$, assumed to have the vinyl structure shown in Figure $3 c$, is formed from tri-isopropyl phosphite. Predominant loss of water (to yield a fragment ion of $\mathrm{m} / z$ 91) at low energies in both instruments indicates the presence of hydroxyl groups in this ion. Fragmentation to yield the ion $\mathrm{PO}_{2} \mathrm{H}_{2}^{+}$of $\mathrm{m} / z 65$ dominates at higher collision energies in the FT-ICR instrument. A structurally characteristic direct bond cleavage is also observed [production of the ion of $m / z 27\left(\mathrm{C}_{2} \mathrm{H}_{3}^{+}\right)$]. Finally, the cyclic ion of $m / z 109$, protonated ethylene phosphate, shows very different behavior from the other ions studied: The most abundant fragment ion does not contain phosphorus $\left(\mathrm{C}_{2} \mathrm{H}_{5} \mathrm{O}^{+}, \mathrm{m} / \mathrm{z}\right.$ 45) (Figure 4).

The results obtained for the isomeric reference ions of $m / z 109$ demonstrate that (1) several different isomers of $m / z 109$ exist as stable species; (2) these isomeric ions are readily distinguished; and (3) the structure of each ion of $m / z 109$ depends on the phosphorus-containing part of the neutral precursor. Thus, characterization of the fragment ion of $\mathrm{m} / z 109$ yields information about the phosphorus-containing part of the neutral phosphorus ester.

The CAD data obtained for the fragment ion of $m / z 109$ formed from a few of the aryl thiophosphates are included in Table 1. Figure 5 shows the production of the fragment ion of $m / z 109$ by CAD of the isolated molecular ion of diethyl 4-chlorophenyl thiophosphate, followed by CAD of the fragment ion of $m / z 109$. The $20 \mathrm{eV}$ CAD spectrum measured for the ion of $\mathrm{m} / z 109$ is very simple, containing only two fragment ions ( $m / z 81$ and 91). Comparison of this spectrum with the CAD spectra obtained for the isomeric reference ions discussed earlier reveals that the fragment ion of $m / z 109$ obtained from diethyl 4-chlorophenyl thiophosphate has the same structure as the reference ion produced from triethyl phosphate and triethyl phosphite. Similar results were obtained for the fragment ion of $m / z 109$ generated from diethyl phenyl thiophosphate (Table 1): $25 \mathrm{eV}$ collisional activation of the ion of $m / z 109$ produces the granddaughter inns of $m / z 81$ and 91 with the same relative abundances as are obtained for the ethyl reference ion.

\section{Aromatic Fragment Ion}

Investigation of the dissociation characteristics of other abundant fragment ions of the aryl thiophosphates, including those appearing at $m / z 125,105$, and 91, resulted in the discovery of another type of fragment ion common to all of the aromatic compounds studied. This ion has a mass value that can be explained on the basis of a specific rearrangement reaction: The mass value depends on the substitution of the aromatic ring as well as the alkyl groups on the phosphorus part of the parent molecule. After a detailed discussion of a 
few specific cases, a mechanism is proposed for the reaction.

An ion of $m / z 125$ is among the most abundant fragment ions (Figure 2; Table 1) formed by electron ionization of dimethyl 4-chlorophenyl thiophosphate (an analog of the pesticide Methyl parathion) [23]. Others [3-7] have suggested that the fragment ion of $m / z 125$ obtained from simple organophosphorus esters has the dimethyl structure illustrated in Scheme II; however, this does not appear to be true for the aromatic esters studied here. The $40 \mathrm{eV}$ CAD of the isolated fragment ion of $m / z 125$ from dimethyl 4chlorophenyl thiophosphate yields three granddaughter ions: those of $m / z 89,90$, and 99 (Figure 6b). The fragment ions of $m / z 89$ and 90 result from the loss of 35 and $36 \mathrm{Da}$ and indicate the presence of chlorine in the precursor ion $(m / z 125)$. Loss of $26 \mathrm{Da}$ (production of the fragment ion of $m / z$ 99) corresponds to the loss of acetylene from the precursor ion. All of these frag- mentations are unlikely for an ion of the dimethyl structure shown in Scheme II. Loss of acetylene, however, is common for aromatic ions. Observation of this fragmentation, together with the evidence for the presence of chlorine, strongly suggests that the fragment ion of $\mathrm{m} / z 125$ contains the aromatic portion of the precursor ion.

On the basis of the previously described observations, the structure shown in Scheme IIIa is suggested for the fragment ion of $m / z 125$ from dimethyl 4-chlorophenyl thiophosphate. Reference ions with the proposed aromatic structure are readily obtained from substituted toluenes (Scheme IIIb). Selection and isolation of the fragment ion of $\mathrm{m} / \mathrm{z} 125$ of 4-chlorotoluene, followed by $C A D$, produced the fragment ions of $m / z 89,90$, and 99 in the same ratios (Figure 6a) as were observed on CAD of the fragment ion of the compound discussed earlier (Figure 6b; Scheme IIIc). Another reference ion of $m / z 125$ was generated

Table 1. Dissociation products obtained for the organophosphorus ions studied ${ }^{\text {" }}$

\begin{tabular}{|c|c|c|}
\hline \multicolumn{3}{|c|}{ Diethyl phenyl thiophosphate } \\
\hline \multirow[t]{7}{*}{ MS MS $^{b}$} & \multicolumn{2}{|c|}{ CAD of $\mathrm{M}^{+\cdot}$ of $m / 2246$} \\
\hline & $10 \mathrm{eV}$ & $218(45), 110(35), 109(53), 105(92), 104(100), 94(6), 91(6)$ \\
\hline & $30 \mathrm{eV}$ & $\begin{array}{l}218(33), 190(7), 137(20), 110(57), 109(97), 105(100), 104(98), 94(22), \\
91(39), 81(67), 78(15), 63(<5)\end{array}$ \\
\hline & $50 \mathrm{eV}$ & $\begin{array}{l}218(35), 190(15), 137(16), 110(60), 109(100), 105(83), 104(76), 103(9), \\
94(24), 91(52), 81(100), 78(2), 77(15), 65(15), 63(10), 27(13)\end{array}$ \\
\hline & $75 \mathrm{eV}$ & $\begin{array}{l}218(20), 190(16), 137(9), 110(40), 109(69), 105(48), 104(41), 103(9), \\
94(19), 91(47), 81(100), 78(20), 77(18), 65(15), 63(16), 27(21)\end{array}$ \\
\hline & $100 \mathrm{eV}$ & $\begin{array}{l}218(18), 190(12), 137(10), 110(30), 109(47), 105(31), 104(27), 94(16), \\
91(38), 81(100), 78(26), 77(26), 65(18), 63(24), 51(10), 27(32)\end{array}$ \\
\hline & $125 \mathrm{eV}$ & $\begin{array}{l}218(22), 190(15), 110(29), 109(39), 105(32), 104(28), 94(14), 91(30) \\
81(100), 78(19), 77(30), 65(20), 63(35), 51(30), 50(11), 47(25), 27(48)\end{array}$ \\
\hline \multirow[t]{6}{*}{$\mathrm{MS}^{3}$} & CAD of $t$ & he fragment ion of $m / 2109^{c}$ \\
\hline & $13 \mathrm{eV}$ & $91(78), 81(100)$ \\
\hline & CAD of $t$ & the fragment ion of $m / 2105^{\circ}$ \\
\hline & $20 \mathrm{eV}$ & $77(100)$ \\
\hline & CAD of $t$ & he fragment ion of $m / z 104^{c}$ \\
\hline & $20 \mathrm{eV}$ & $103(34), 78(100)$ \\
\hline \multicolumn{3}{|c|}{ Diethyl 4-chlorophenyl thiophosphate } \\
\hline \multirow[t]{7}{*}{ MS /MS } & CAD of 1 & $\mathrm{M}^{+\cdot}$ of $m / z 280$ \\
\hline & $10 \mathrm{eV}$ & $252(66), 224(18), 144(54), 139(83), 138(56), 109(100)$ \\
\hline & $30 \mathrm{eV}$ & $\begin{array}{l}252(21), 224(11), 144(51), 139(55), 138(34), 137(18), 128(24), 109(100), \\
103(12), 91(28), 81(38), 29(7)\end{array}$ \\
\hline & $50 \mathrm{eV}$ & $\begin{array}{l}252(21), 224(8), 144(47), 139(46), 138(29), 137(12), 128(27), 109(100) \\
103(20), 91(47), 81(84), 65(8), 29(17), 27(4)\end{array}$ \\
\hline & $75 \mathrm{eV}$ & $\begin{array}{l}252(18), 224(7), 144(42), 139(37), 138(22), 128(25), 109(86), 91(45), \\
81(100), 77(8), 65(13), 29(23), 27(10)\end{array}$ \\
\hline & $100 \mathrm{AV}$ & $\begin{array}{l}252(13), 144(31), 139(28), 138(16), 128(21), 109(71), 91(41), 81(100) \\
77(10), 65(13), 29(25), 27(16)\end{array}$ \\
\hline & $125 \mathrm{eV}$ & $\begin{array}{l}252(16), 144(26), 139(24), 128(17), 109(56), 108(8), 103(15), 91(33) . \\
81(100), 77(14), 65(18), 29(27), 27(26)\end{array}$ \\
\hline \multirow[t]{2}{*}{ MS $^{3}$} & CAD of $t$ & the fragment ion of $m / z 109^{\circ}$ \\
\hline & $10 \mathrm{eV}$ & $91(46), 81(100)$ \\
\hline
\end{tabular}


Table 1. Dissociation products obtained for the organophosphorus ions studied ${ }^{a}$ (continued)

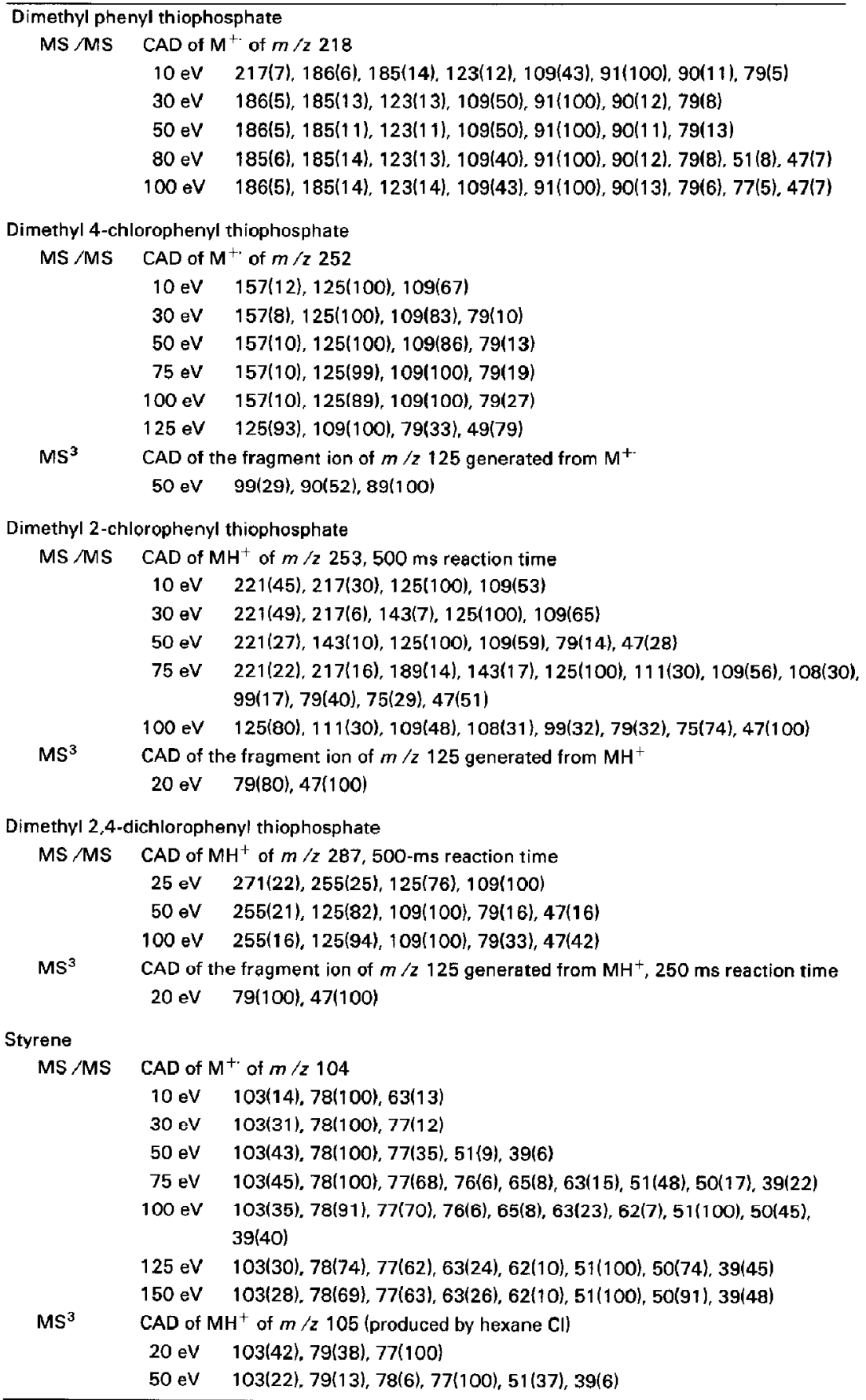

\footnotetext{
${ }^{a}$ Ions with less than $5 \%$ relative abundance are not reported unless they are discussed in the text. For collisional activation, the energy reported is the estimated laboratory kinetic energy, based on ref 14 . Argon pressure was $1 \times 10^{-7}$ torr, reaction time $100 \mathrm{~ms}$ unless otherwise specified.

${ }^{5} \mathrm{MS}$ MS, tandem mass spectrometry.

${ }^{\mathrm{C}}$ The signal-to-noise ratio for these data was too low to allow accurate measurement of the relative abundances.
} 


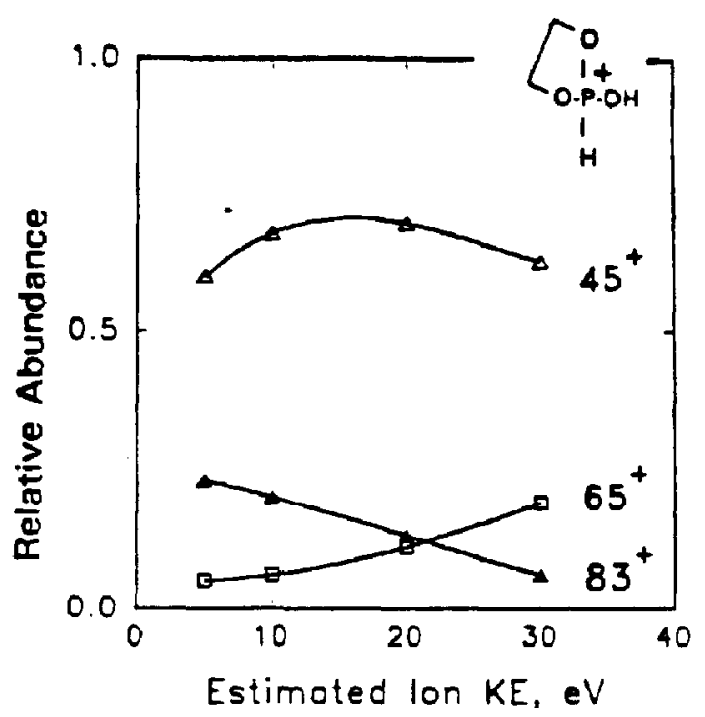

Figure 4. Energy-resolved mass spectra of the cyclic reference ion of $m / z 109$ produced by chemical ionization of ethylene phosphonate (see text).

from 2-chlorotoluene in the same manner as for 4chlorotoluene. The CAD spectrum of this ion is identical to that from 4-chlorotoluene. Thus, it is not possible to assign the position of the chlorine in the fragment ion on the basis of these data alone. Finally, it was conclusively demonstrated that the structure of the fragment ion of $m / z 125$ from dimethyl 4chlorophenyl thiophosphate is not the dimethyl structure shown in Scheme II by generating a reference ion with this structure by $30 \mathrm{eV}$ electron ionization of trimethyl thiophosphate (Scheme IIId). Collisionactivated dissociation of this fragment ion results in loss of formaldehyde ( $m / z 79$, Figure $6 c)$. This finding conclusively rules out the phosphorus-containing structure.

Scheme IV shows a conceivable mechanism for a rearrangement that involves transfer of a methylene unit to the aromatic ring in the molecular ion of dimethyl 4-chlorophenyl thiophosphate and elimination of $\mathrm{CH}_{3} \mathrm{OP}(\mathrm{O})(\mathrm{SH}) \mathrm{O}$ to yield the ion $\mathrm{C}_{7} \mathrm{H}_{6} \mathrm{Cl}^{+}$ $(m / z$ 125). The first step involves isomerization of the molecular ion to a distonic ion $\mathbf{i}$. The molecular ions of organophosphorus compounds are known to isomerize to thermodynamically more stable distonic structures after innization in tandem mass spectrometers [16, 23]. Isomerization of the molecular ion is followed by radical addition to the aromatic ring to form the intermedi-

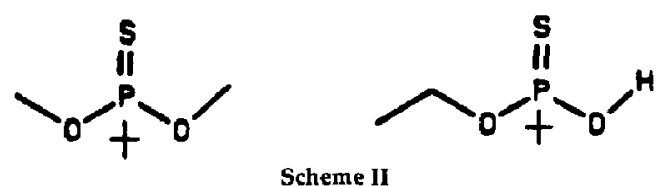

a

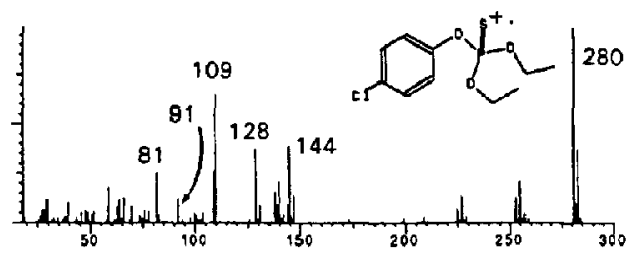

b
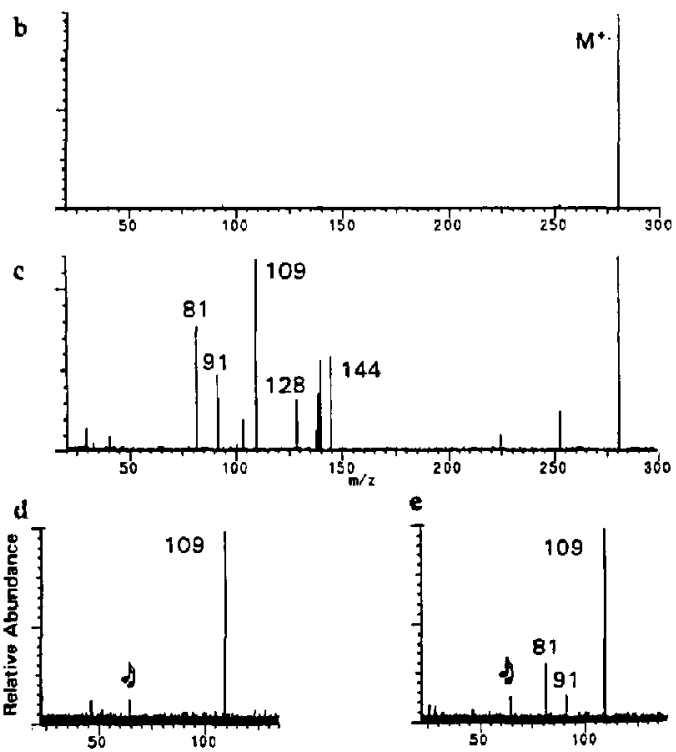

Figure 5. $\mathrm{MS}^{3}$ experiment for diethyl 4-chlorophenyl thiophosphate: (a) $12 \mathrm{eV}$ electron ionization mass spectrum; (b) isolation of the molecular ion of $m / z 280$; (c) $40 \mathrm{eV} \mathrm{CAD} \mathrm{spectrum} \mathrm{of} \mathrm{the}$ molecular ion; (d) isolation of the fragment ion of $\mathrm{m} / \mathrm{z} 109$; (e) 20 $\mathrm{eV}$ CAD spectrum of the fragment ion of $m / z$ 109. Argon was used as the collision gas at a nominal pressure of $1 \times 10^{-7}$ torr; CAD reaction time was $100 \mathrm{~ms}$. The symbol indicates interference caused by a local radio station.

ate ii. The fragment ion of $m / z 125$ is produced by the cleavage of two $\mathrm{C}-\mathrm{O}$ bonds in this intermediate ion. The rate-determining step for the proposed rearrangement reaction is likely to be the isomerization of the molecular ion to the distonic ion $\mathbf{i}$ because this reaction is estimated to be endothermic (by approximately $6 \mathrm{kcal} / \mathrm{mol}$ for the molecular ion of trimethyl thiophosphate) [15].

On the basis of the mechanism discussed above, CAD of the molecular ion of dimethyl phenyl thiophosphate is expected to produce an abundant fragment ion of $m / z 91$ as a result of methylene transfer to the aromatic ring (Scheme Va). This fragment ion is indeed observed in the CAD spectrum (Figure 7a). Instead of an ion of $m / z 91$, the molecular ion of diethyl phenyl thiophosphate yields a major fragment ion of $m / z 105$ on CAD (Figure $7 b$ ). Formation of this ion is in accordance with the proposed mechanism, which now involves transfer of $\mathrm{CHCH}_{3}$ to the phenyl ring (Scheme IV). $\mathrm{MS}^{3}$ experiments were performed on the fragment ion of $m / z 105$ discussed above to deter- 
a<smiles>CO[Pb]([S-])(OC)O[Na]</smiles>

b

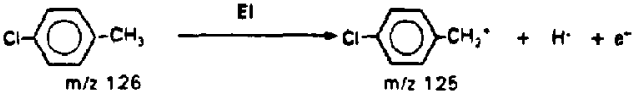

d

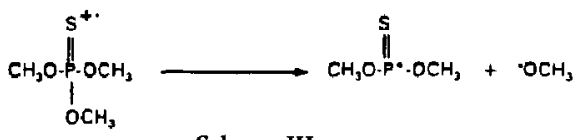

Scheme III

mine whether this ion has the structure expected on the basis of the proposed mechanism. On CAD, the ion of $m / z 105$ decomposes to yield an ion with a mass value corresponding to the phenyl cation $\left(\mathrm{C}_{6} \mathrm{H}_{5}^{+}\right.$of $m / z$ 77; Table 1 ), which strongly suggests that the fragmenting ion is aromatic. Examination of the CAD spectrum measured for a reference ion of $\mathrm{m} / z 105$ obtained by protonating styrene shows that this ion has the same structure(s) as the fragment ion of $m / z 105$ of diethyl phenyl thiophosphate. This observation provides support for a fragmentation mechanism for ionized diethyl phenyl thiophosphate analogous to that shown in Scheme IV for 4-chlorophenyl dimethyl thiophosphate (transfer of $\mathrm{CHCH}_{3}$ occurs for the ethyl derivative, transfer of $\mathrm{CH}_{2}$ for the methyl derivative). The actual structure of the fragment ion of $\mathrm{m} / \mathrm{z} 105$ of diethyl phenyl thiophosphate remains uncertain because it is conceivable that styrene can accept a proton on the aromatic ring as well as on the substituent; both product ions are expected to be stable (stabilized by several resonance forms). However, indirect evidence supports the formation of an intermediate analogous to iii from diethyl phenyl thiophosphate: The CAD spectrum of the fragment ion of $m / z 104$ indicates that this ion has the structure of the molecular ion of styrene $(\mathrm{m} / z \mathrm{z} 104$; Table 1$)$. The formation of ionized styrene from ionized diethyl phenyl thiophosphate is readily explained on the basis of a McLafferty rearrangement in the intermediate iii, as shown later.
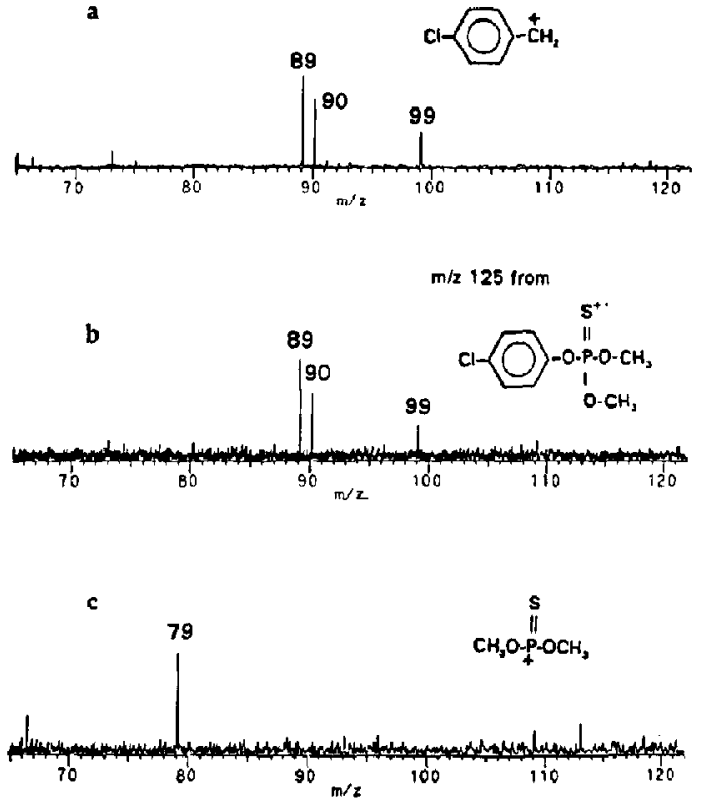

Figure 6. (a) $M S^{3}$ experiment involving the generation and isolation of the molecular ion of 4-chlorotoluene followed by CAD and isolation of the fragment ion of $m / z$ 125; the final spectrum (CAD of the ion of $m / z$ 125) is illustrated. The energy of the CAD was $35 \mathrm{eV}$; argon was the collision gas at a nominal pressure of $1 \times 10^{-7}$ torr, and reaction time was $100 \mathrm{~ms}$ (see text). (b) $\mathbf{M S}^{3}$ experiment involving the generation and isolation of the molecular ion of dimethyl 4-chlorophenyl thiophosphate followed by CAD and isolation of the fragment ion of $m / z$ 125; the final spectrum (CAD of the ion of $m / z 125$ ) is illustrated. (c) $50 \mathrm{eV} \mathrm{CAD}$ spectrum of the fragment ion of $m / z 125$ produced from trimethyl thiophosphate (see text).

\section{Protonated Molecules}

The fragmentation behavior of the protonated molecules of some of the thiophosphates was also studied because much of the literature on analytical applications of mass spectrometry detail studies of protonated molecules rather than of molecular ions [3-5, 23]. Protonated dimethyl 2-chlorophenyl thiophosphate and dimethyl 2,4-dichlorophenyl thiophosphate (an analog of the pesticide Chlorthion) [28] dissociate to produce abundant fragment ions of $m / z 109$ and 125 (Table 1;

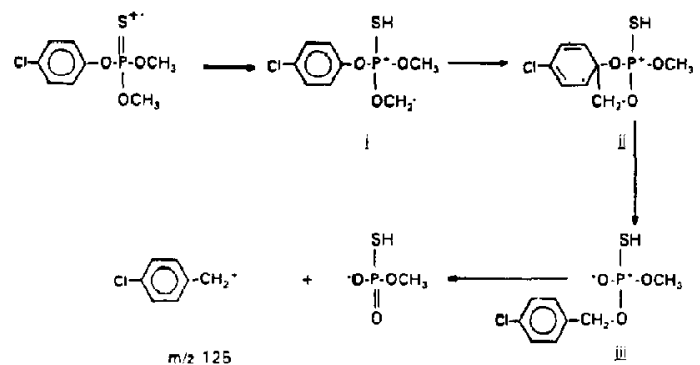

Scheme IV 
$\mathbf{a}$

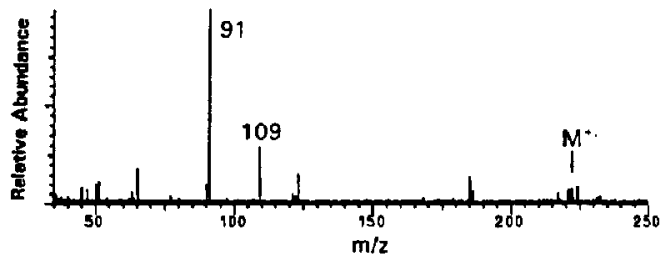

b

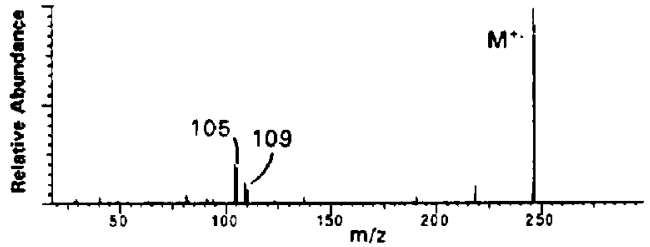

Figure 7. (a) $200 \mathrm{eV}$ CAD spectrum of the molecular ion of dimethyl phenyl thiophosphate; (b) $10 \mathrm{eV} \mathrm{CAD} \mathrm{spectrum} \mathrm{of} \mathrm{the}$ molecular ion of diethyl phenyl thiophosphate.

Figures 8 and 9). Two dissociation products dominate the spectra of the fragment ion of $\mathrm{m} / z 125$ of protonated dimethyl 2,4-dichlorophenyl thiophosphate-the ions of $m / z 79$ and 47 (Table 1). This finding indicates that the fragment ion of $\mathrm{m} / z 125$ is not aromatic; it has a structure similar to that of the reference ion of $m / z 125$ generated from trimethyl thiophosphate (Figure 6c; Scheme IIId). Collision-activated dissociation performed on the fragment ion of $m / z 125$ generated from protonated dimethyl 2-chlorophenyl thiophosphate yields similar results (Table 1). These findings conclusively show that the fragment ion of $m / z 125$ generated from protonated dimethyl 2chlorophenyl thiophosphate and dimethyl 2,4dichlorophenyl thiophosphate is different from that obtained from the molecular ion of dimethyl 4chlorophenyl thiophosphate. Considering the proposed mechanism for the formation of the ion of $\mathrm{m} / z 125$ from the molecular ions (Scheme IV), it is not surprising that this aromatic fragment is not generated from the protonated molecules.

a<smiles>COP(=O)(OC)Oc1ccccc1OP(=S)(OC)OC</smiles>

b<smiles>C=Cc1ccccc1CC(=O)OCC</smiles>

Scheme $V$
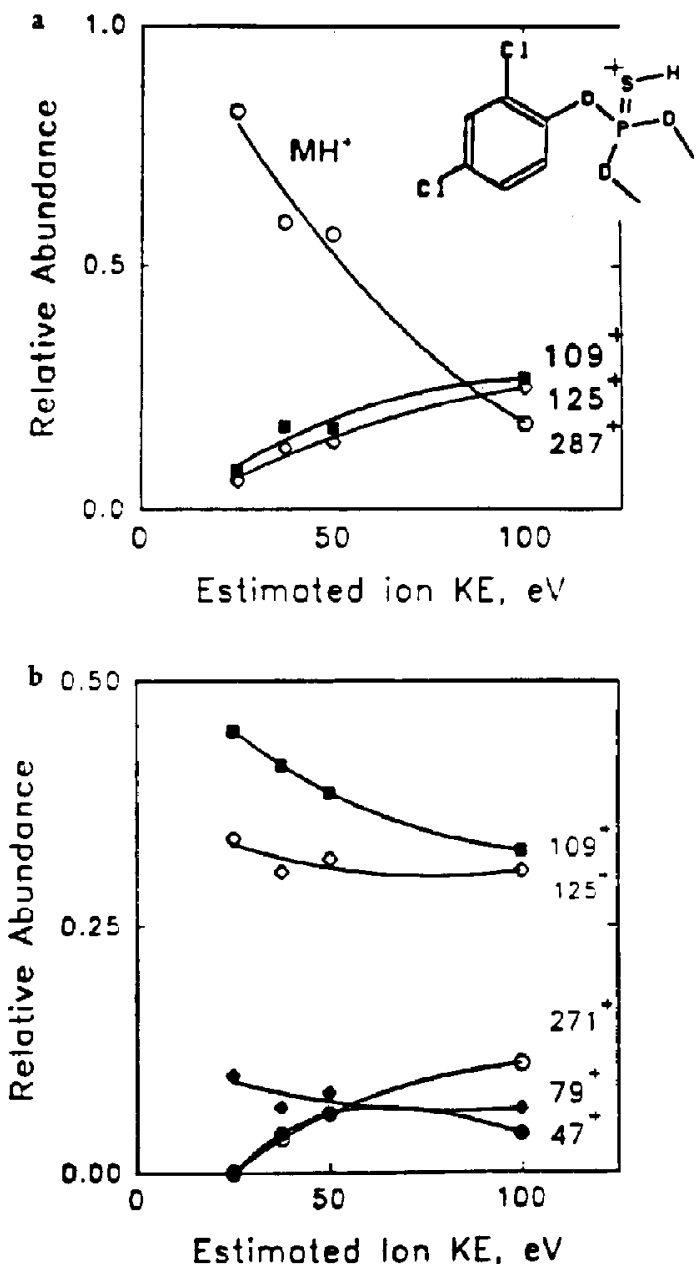

Figure 8. Energy-resolved mass spectra of the $(\mathrm{MH})^{+}$ion of dimethyl 2,4-dichlorophenyl thiophosphate. The total ion current was calculated by (a) including and (b) excluding the parent ion.

\section{Conclusions}

The structures of two fragment ions commonly produced on collisional activation of the molecular ions of aromatic thiophosphates were characterized by using $\mathrm{MS}^{3}$ experiments involving consecutive CAD. Energyresolved CAD readily distinguishes among the four stable isomeric structures possible for the fragment ion of $m / z$ 109. The structure of this fragment ion is characteristic of the phosphorus-containing part of the compounds studied. Another abundant fragment ion was shown to arise from a complex rearrangement reaction of the molecular ion in which an alkylene group is transferred from the phosphorus-containing part of the molecular ion to the aromatic part prior to or during fragmentation. The mass value of the product ion is therefore dependent on the substitutents on the aromatic ring as well as on the phosphoruscontaining part of the precursor molecule: The 


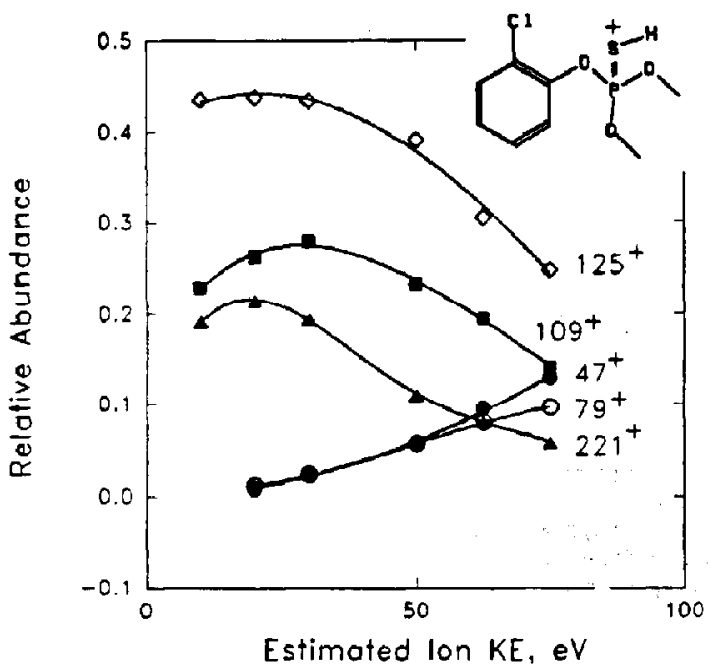

Figure 9. Energy-resolved mass spectra of the $(\mathrm{MH})^{+}$ion of dimethyl 2-chlorophenyl thiophosphate. The total ion current was calculated by excluding the parent ion.

protonated molecules of the aryl thioesters fragment differently than the molecular ions and do not yield a structurally characteristic aromatic fragment ion.

\section{Acknowledgments}

The authors thank Graham Cooks for access to a triple quadrupole instrument; Craig Claussen for work on the reference ions of $m / z 109$; and Rebecca S. Smith for tandem mass spectrometry work on some of the compounds. The Lubrizol Corporation and the National Science Foundation (grant no. CHE-9107121) are gratefully acknowledged for financial support.

\section{Appendix}

\section{Registry Numbers}

Trimethyl phosphate [512-56-1], trimethyl phosphite [121-45-9], trimethyl thiophosphate [152-18-1], triethyl phosphate [78-40-0], triethyl phosphite [122-52-1], tri-isopropyl phosphite [923-99-9], dimethyl propyl phosphate [51463-65-1 or 4202-14-6], dimethyl phenyl thiophosphate [33576-92-0], dimethyl 4chloropheny] thiophosphate [5314-03-4], dimethyl 2chlorophenyl thiophosphate [13194-51-9], diethyl phenyl thiophosphate [32345-29-2], styrene [100-42-5], 4-chlorotoluene [106-43-4], 2-chlorotoluene [95-49-8], $\mathrm{d}_{8}$-isopropanol [22739-76-0].

\section{References}

1. Thruston, A. D. Jr.; Richardson, S. D.; McGuire, J. M.; Collette, T. W.; Trusty, C. D. I. Am. Soc. Mass Spectrom. 1991, 2, 419-426.

2. Wilkins, J. P. G. Pestic. Sci. 1990, 29, 163-181.

3. Roach, J. A. G.; Andrzejewski, D. In Applications of New MS Techniques on Pesticide Chemistry, Rosen, J. O., Ed.; Wiley: New York, 1987.

4. Roach, J. A. G.; Carson, L. J. I. Assac. Off. Anal. Chem. 1987, $70,439-442$.

5. (a) Hummel, S. V.; Yost, R. A. Org. Mass. Spect. 1986, 21, 785 791; (b) Johnson, J. V.; Yost, R. A.; Kelley, P. E.; Bradford, D. C. Anal. Chem. 1990, 62, 2162-2172.

6. Singh, A. K.; Hewetson, D. W.; Jordon, K. C.; Ashraf, M. J. Chromatogr. 1986, 369, 83-96.

7. Cooks, R. G.; Gerrard, A. F. J. Chem. Soc. (B). 1968, 1327-1333.

8. Holmstead, R. L.; Casida, J. E. I. Assoc. Off. Amal. Chem. 1974, $57,1050-1055$.

9. Sass, S.; Fisher, T. L. Org. Mass Spectrom. 1979, 14, 257-264.

10. Busch, K. L.; Bursey, M. M.; Haas, J. R.; Sovecool, G. W. Appl. Spectrosc. 1978, 32, 388-399.

11. Cload, P. A.; Hutchínson, D. W. Org. Mass Spectrom. 1983, 18, 57-59.

12. Kuivalainen, T.; Kostiainen, R., submitted.

13. Farrell, J. T, Lin, P.; Kenllämà, II. I. Arual. Chim. Acta 1991, $246,227-332$.

14. Grosshans, P. B.; Marshall, A. G. Int. I. Mass Spect. Ion Processes 1990, 100. 347.

15. Zeller, L.; Farrell, J.; Vainiotalo, P.; Kenttämaa, H. I. I. Am. Chem. Soc. 1992, 114, 1205-1215.

16. Slayback, J. R. B.; Story, M. S. Industrial Research \& Dezelopment 1981, 129.

17. Vainiotalo, P.; Kenttämaa $r$ H. I.; Mabud, M. A.; O'Lear, J. R.; Cooks, R. G. J. Am. Chem. Soc. 1987, 109, 3188-3194.

18. Lias, S. G.; Bartmess, J. E.; Liebman, J. F.; Holmes, J. L.; Levin, R. D.; Mallard, G. J. Phys. Chem. Ref. Data 1988, 17.

19. Safe, S. Mass Spectrometry of Pesticides and Pollutants, Cleveland: CRC Press, 1973.

20. Bafus, D. A.; Gallegos, E. J.; Kiser, R. W. J. Phys. Chem. 1966, 70, 2614-2619.

21. Snyder, A. P.; Harden, C. S. Org. Mass Spectrom. 1990, 25, 53-60.

22. Hammerum, S. Mass Spectrom. Rev. 1988, 7, 123-202.

23. Stan, H.-J.; Abraham, B.; Jung, J.; Kellert, M.; Steinland, K. Fresenius Z. Anal. Chem. 1977, 287, 271-285.

24. McLafferty, F. W.; Bockoff, F. M. J. Am. Chem. Soc. 1979, 101, 1783-1786.

25. Dunbar, R. C. J. Am. Chem. Soc. 1975, 97, 1382-1384.

26. Jackson, J.-A. A.; Lias, S. G.; Ausloos, P. I. Am. Chem. Soc. 1977, 99, 7515-7521.

27. Ausloos, P. J. Am. Chem. Soc. 1982, 104, 5259 5265.

28. Cairns, T.; Siegmend, E. G. I. Assac. Off. Anal. Chem. 1987, 70 , 858-862. 